http://jmscr.igmpublication.org/home/ ISSN (e)-2347-176x ISSN (p) 2455-0450 crossref DOI: https://dx.doi.org/10.18535/jmscr/v8i8.35

Journal Of Medical Science And Clinical Research

\title{
The Effect of Nebulised Magnesium Sulphate on the Incidence of Post Operative Sore Throat
}

\author{
Authors \\ Dr Kumar B.G ${ }^{1}$, Dr Mallika Balakrishnan ${ }^{2}$, Dr Bhagyalekshmi Ramesh ${ }^{3}$ \\ ${ }^{1}$ Registrar, Kerala Institute of Medical Sciences, Trivandrum (India) \\ ${ }^{2}$ Additional professor, Regional Cancer Centre, Trivandrum (India) \\ ${ }^{3}$ Assistant Professor, Regional Cancer Centre, Trivandrum (India)
}

\begin{abstract}
Background: Postoperative sore throat (POST) is a well-recognized complication after general anesthesia (GA), with its incidence ranging up to 6.6 to 90\%(1). This particular study used magnesium sulfate in the nebulized form at very low doses to study the effect it has on reducing the sensation of postoperative sore throat.

Aims and Objectives: The present study was conducted to compare the efficiency of preoperative nebulization of normal saline and magnesium sulphate in reducing the incidence of POST following GA.

Methods: After obtaining Institutional ethical committee and Clinical Trials Registry-India clearance (CTRI/2017/06/008), thestudy was conducted in 45 patients, requiring General Anaesthesia (GA) with endotracheal intubation for 2 or more hours. Patients with neuromuscular disease, hypersensitivity to drugs and those undergoing neck surgeries were excluded. The study population was nebulized with $3 \mathrm{ml}$ of $225 \mathrm{mg}$ magnesium sulphate 5 minutes prior to induction. The results obtained were compared with an equal number of patients fulfilling the inclusion criteria on whom normal saline was used as a standard of nebulization for 15 minutes and in whom the data on post-operative sore throat was already collected and available for use. The cuff pressure was checked just after intubation and then every 30 minutes, maintained at $20 \mathrm{~cm} \mathrm{H2O}$. No nasogastric tube was inserted. Presence of POST at rest and on swallowing was noted immediately after extubation, and subsequently at $2 h, 4 h, 10 h$, and $24 h$ postoperatively. Association of POST between the two groups was assessed using the chi-square test

Results: With respect to age, gender, and ASA status, there was no significant difference in POST between the two groups. POST at rest at $0 h$ and $2 h$ between the two groups didn't show any significant difference. There was a significant difference in POST at rest between group $A$ and group B at $4 h(p=0.011), 10 h$ $(p=0.003)$ and $24 h(p=0.003)$ using chi square test. With respect to POST on swallowing, there was a significant difference in at $2 \mathrm{~h}(p=0.008), 4 \mathrm{~h}(0.001), 10 \mathrm{~h}(0.001)$ and $24 \mathrm{~h}(0.001)$ between the two groups. Conclusions: MgSO4significantly reduces the incidence of POST compared to normal saline

Keywords: Endotracheal intubation, magnesium sulphate nebulization, post operative sore throat.
\end{abstract}

\section{Introduction}

Postoperative sore throat occurs in 6.6 to $90 \%$ of intubated patients and is the most common complaint after tracheal intubation ${ }^{(1)}$. Emergence from general anaesthesia is frequently complicated by endotracheal tube induced coughing. This can result in potentially dangerous patient movement, hypertension, tachycardia or 
other arrhythmias, myocardial ischemia, surgical bleeding, bronchospasm and increase in intracranial and intraocular pressure. Laryngeal edema and mucosal ischemia are also commonly associated with intubations ${ }^{(2,3)}$

Postoperative sore throat is attributed to factors such as tube size, lateral wall pressure, movement and hypotension. Cuff related tracheal damage is influenced by both lateral wall pressure and the duration of intubations. To prevent the drop in tracheal mucosal capillary perfusion pressure and to avoid ischemic damage, the lateral wall cuff pressure exerted by the cuff should not exceed the mean mucosal capillary perfusion pressure that is around $30 \mathrm{~cm}$ of water. Ideally the pressure exerted against the tracheal wall by the cuff of ETT should be low enough to allow adequate capillary mucous membrane blood flow and high enough to prevent air leaks and aspiration of regurgitated gastric content. The use of nitrous oxide during general anaesthesia which is known to diffuse into endotracheal tube cuffs and the lack of frequent control of intracuff pressure during the perioperative period are most important factors that contribute to the high incidence of excessive intracuff pressure during the intraoperative period. Coughing induced by an ETT can complicate emergence from general anaesthesia. Irritant or stretch stimuli in the trachea caused by the tube and its cuff are presumed mechanisms. Rapidly adapting stretch receptors (RAR) in the tracheal mucosa are believed to be irritant receptors involved in the cough reflex ${ }^{(4,5)}$

Intravenous magnesium sulphate is extensively and routinely used in anaesthetic as well as critical care for a wide range of conditions such as tocolysis, toxemia of pregnancy, asthma, and torsades de pointes $^{(6)}$. It is known that NMDA (N-Methyl D-Aspartate) receptors play a role in nociception and inflammation ${ }^{(7,8)}$. Magnesium sulphate works as an antagonist of the NMDA receptor $^{(9)}$. This particular study aims to use magnesium sulphate in the nebulized format at very low doses from that normally used in other conditions to study the effect it has in reducing the sensation of post-operative sore throat

\section{Material and Methods}

With the level of significance (alpha) $=0.05$, and power of $80 \%$, sample size required was 40 per group. To accommodate any exclusion, 45 patients for each group were selected. The study was conducted in the selected 45 cases, after acquiring ethical committee approval and written informed consent and the results were compared with an equal number of patients meeting the inclusion criteria, in whom normal saline was used for nebulization pre operatively for 15 minutes, following which GA was induced 5 minutes later. The data on the post-operative sore throat at rest and on swallowing was obtained from the routine normal saline nebulized group and was used to compare with the study group acquired data.

Patients included in study were of either gender, aged between 18 and 60 years belonging to American Society of Anesthesiologist (ASA) 1 or 2 statuses undergoing elective surgery of approximately $2 \mathrm{~h}$ or more duration under GA requiring tracheal intubation. Patients with neuromuscular disease, allergy or hypersensitivity of drugs, undergoing neck surgeries, and laparoscopic surgeries were excluded.

All patients were kept fasting overnight and premedicated with oral alprazolam $0.5 \mathrm{mg}$ and ranitidine $150 \mathrm{mg}$ on night before surgery and on the morning of surgery, as per standard department protocol.

Five minutes prior to the induction of anesthesia, patients in the study group were nebulized with 3 $\mathrm{ml}$ of $225 \mathrm{mg}$ isotonic nebulized magnesium sulfate for $15 \mathrm{~min}$ in the holding area. The solution for nebulization was administered by an anesthesiologist not associated with the management of the case. The anesthesiologist anesthetizing the case and those evaluating the post-operative sore throat were blinded. The patient was shifted to the operation theatre, 5 minutes after the nebulization was completed. In the operation theater, after connecting the patient 
to standard ASA monitoring, anaesthesia was induced with fentanyl $2 \mathrm{mcg} / \mathrm{kg}$ and propofol 2 $\mathrm{mg} / \mathrm{kg}$. Tracheal intubation was facilitated by atracurium $0.6 \mathrm{mg} / \mathrm{kg}$, and the trachea intubated with soft seal cuffed sterile polyvinyl chloride tracheal tube (Portex Limited CT 21, 6JL, UK) of $7 \mathrm{~mm}$ inner diameter in female and $8 \mathrm{~mm}$ in male patients. The tracheal tube cuff was inflated with air. The cuff pressure was checked just after intubation using handheld tracheal cuff pressure monitor (Portex Cuff Inflator/Pressure Gauge, SIMS Portex, Hythe, Kent, UK) and then every 30 minutes till end of surgery and maintained at 20 $\mathrm{cm}$ of $\mathrm{H} 2 \mathrm{O}$.Ventilation was controlled, and no nasogastric tube was inserted. Anesthesia was maintained with $66 \%$ nitrous oxide in oxygen with MAC value of isoflurane and intermittent doses of atracurium and fentanyl as required. The last dose of atracurium was given $20 \mathrm{~min}$ prior to extubation. At the end of surgery, the muscle relaxation was reversed with a combination of neostigmine $0.05 \mathrm{mg} / \mathrm{kg}$ and glycopyrrolate 0.01 $\mathrm{mg} / \mathrm{kg}$, before the trachea was extubated, and the patients were shifted to post anesthesia care unit.

Presence of sore throat was noted at rest and on swallowing immediately after extubation, and $2 \mathrm{~h}$, $4 \mathrm{~h}$, 10hand $24 \mathrm{~h}$ postoperatively. In the postoperative ward, patients were also monitored for any drug-related side effects. The results obtained were compared with an equal number of patients fulfilling the inclusion criteria on whom normal saline was used as a standard of nebulization for 15 minutes and in whom the data on post-operative sore throat was already collected and available for use.

For categorical data, frequency and percentage of distribution was calculated and for comparison between groups, Chi square/fisher's exact test was used. Fisher's exact test;

$\mathrm{P}<0.05$ was considered statistically significant. For quantitative (continuous data), mean, standard deviation and range was calculated. For comparison of quantitative data between groups, student's $t$ test was used

\section{Results}

With respect to age, gender, and ASA status, there was no significant difference in POST between the two groups. POST at rest at $0 \mathrm{~h}$ and $2 \mathrm{~h}$ between the two groups didn't show any significant difference. There was a significant. Difference in POST at rest between group A and group B at $4 \mathrm{~h}$ $(\mathrm{p}=0.011), 10 \mathrm{~h}(\mathrm{p}=0.003)$ and $24 \mathrm{~h}(\mathrm{p}=0.003)$ using chi square test. With respect to POST on swallowing, there was a significant difference in POST at $2 \mathrm{~h}(\mathrm{p}=0.008), 4 \mathrm{~h}(0.001), 10 \mathrm{~h}(0.001)$ and $24 \mathrm{~h}(0.001)$ using chi square test.

\section{Post operative sore throat at rest at different time intervals}

\begin{tabular}{|l|c|c|c|}
\hline $\begin{array}{l}\text { Time } \\
(\mathrm{h})\end{array}$ & $\begin{array}{c}\text { Nebulised drug } \\
(\mathrm{n}=45)\end{array}$ & $\begin{array}{c}\text { POST } \\
(\%)\end{array}$ & $\begin{array}{c}\text { Pearson chi-square value } \\
(\mathrm{p} \text {-value })\end{array}$ \\
\hline 0 & $\mathrm{NS}$ & 26 & 0.525 \\
& $\mathrm{MgSO} 4$ & 23 & 0.090 \\
\hline 2 & $\mathrm{NS}$ & 29 & 0.011 \\
\hline 4 & $\mathrm{MgSO} 4$ & 21 & 0.003 \\
& $\mathrm{NS}$ & 26 & 0.003 \\
\hline 10 & $\mathrm{MgSO} 4$ & 14 & \\
\hline 24 & $\mathrm{NS}$ & 20 & 0.03 \\
& $\mathrm{MgSO} 4$ & 15 & 3 \\
\hline
\end{tabular}


Post operative sore throat on swallowing at different time intervals

\begin{tabular}{|l|c|c|c|}
\hline $\begin{array}{l}\text { Time } \\
(\mathrm{h})\end{array}$ & $\begin{array}{c}\text { Nebulised drug } \\
(\mathrm{n}=45)\end{array}$ & $\begin{array}{c}\text { POST } \\
(\%)\end{array}$ & $\begin{array}{c}\text { Pearson chi-square value } \\
(\mathrm{p} \text {-value })\end{array}$ \\
\hline 0 & $\mathrm{NS}$ & 26 & 0.671 \\
\hline 2 & $\mathrm{MgSO} 4$ & 24 & 0.008 \\
& $\mathrm{NS}$ & 35 & 0.001 \\
\hline 4 & $\mathrm{MgSO} 4$ & 23 & 0.0001 \\
\hline 10 & $\mathrm{NS}$ & 32 & 0.001 \\
\hline 24 & $\mathrm{MgSO} 4$ & 23 & \\
\hline
\end{tabular}

$\mathrm{h}=$ hours, $\mathrm{NS}=$ normal saline, $\mathrm{MgSO} 4=$ magnesium sulphate, $\mathrm{POST}=$ Post-operative sore throat

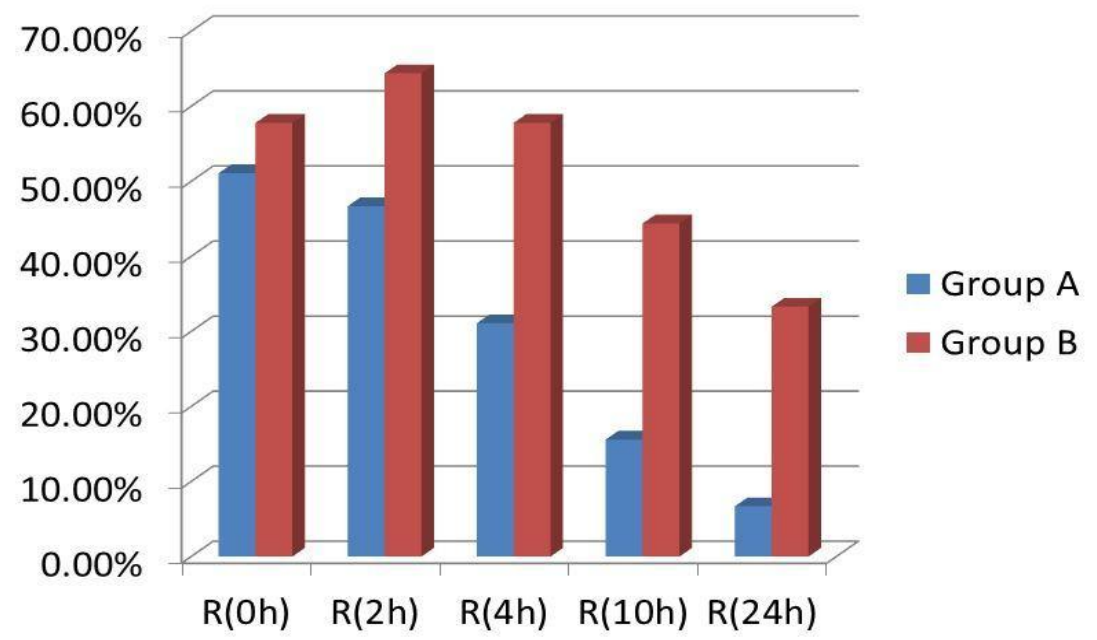

COMPARISON CHART OF POST OPERATIVE SORE THROAT BETWEEN MAGNESIUM SULFATE ( GROUP A) AND NORMAL SALINE (GROUP B ) AT REST (R=REST) AT DIFFERENT TIME INTERVALS

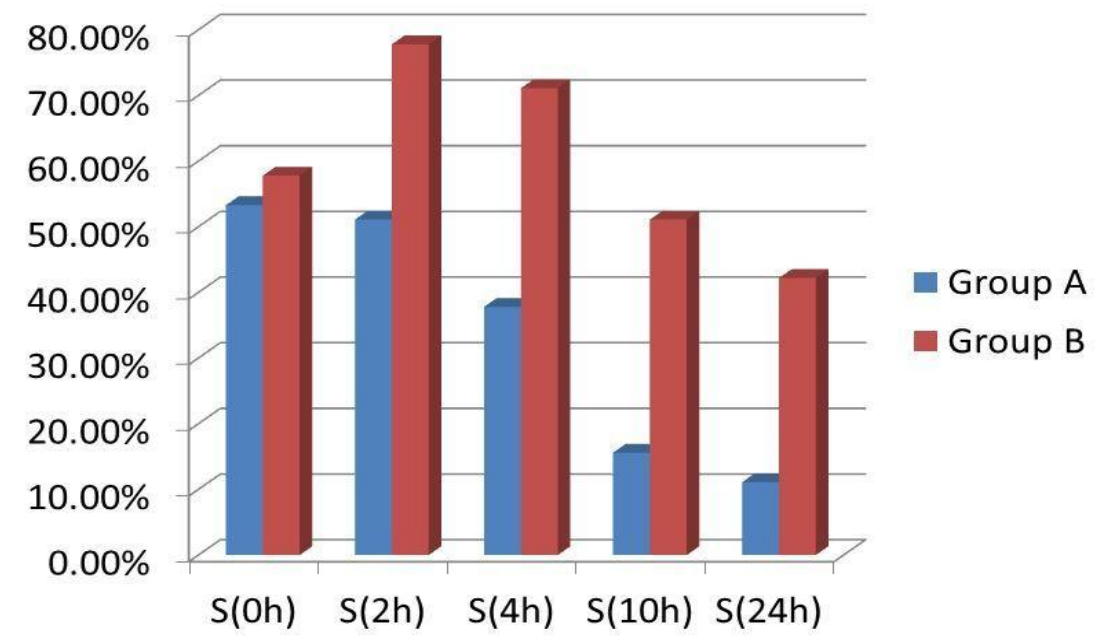

COMPARISON CHART OF POST OPERATIVE SORE THROAT BETWEEN MAGNESIUM

SULFATE ( GROUP A) AND NORMAL SALINE (GROUP B ) ON SWALLOWING

( $S=$ SWALLOWING) AT DIFFERENT TIME INTERVALS 


\section{Discussion}

The causative mechanism for post-operative sore throat could be multiple in origin, including mechanical injury during laryngoscopy and intubation, continuous pressure by the inflated tracheal tube cuff on tracheal mucosa causing damage and dehydration of the mucosa, along with de-epithelialisation and local inflammatory damage of the mucosa. Literature pertaining to the use of nebulized magnesium sulphate for attenuation of POST is scarce.

Numerous non pharmacological and pharmacological measures have been used for attenuating POST with variable success. Among the non pharmacological methods, smaller sized tracheal tubes, careful airway instrumentation, minimizing the number of laryngoscopy attempts, intubation after the full relaxation of the larynx, gentle oropharyngeal suctioning, filling the cuff with an anaesthetic gas mixture, minimizing intracuff pressures $<20 \mathrm{~mm} \mathrm{Hg}$, and extubation when the tracheal tube is fully deflated, have been reported to decrease the incidence of $\mathrm{POST}^{(10)}$.

Endotracheal tube related post-operative sore throat might be a consequence of localized traumatic inflammation of the pharyngeal mucosa .It is known that N-methyl-D-aspartate (NMDA) has a role in nociception and inflammation. ${ }^{(7,8)}$ NMDA receptors are found in peripheral nerves and the central nervous system. ${ }^{(11,12)}$ Magnesium is also an antagonist of the NMDA receptor ion channel. ${ }^{(9)}$ We decided to study the efficacy of magnesium sulphate nebulization to reduce the incidence of POST as the drug was easily available and as nebulization may be a simple, cost-effective method to decrease symptoms of POST.

Our results in the control group were consistent with previous findings. We avoided using lignocaine jelly, to minimize the confounding factors, which could cause disparity and confusion in the accuracy of the results of our study.

Kori et al. ${ }^{(13)}$ Maruyama et al. ${ }^{(14)}$ found a higher incidence and severity of POST, when lignocaine
$2 \%$ jelly was used as a lubricant on the tracheal tube.

The effectiveness of magnesium lozenges $30 \mathrm{~min}$ preoperatively was studied by Borazan et al. ${ }^{(15)}$ found it effective in reducing both incidence and severity of POST in the immediate postoperative period. These results are comparable to our study results.

Gupta et $\mathrm{l}^{(16)}$ also assessed the efficacy of preoperative nebulization of magnesium sulphate and found that the incidence and severity of POST were reduced at rest and on swallowing at all-time points $(P<0.05)$. Though our study couldn't demonstrate an effective reduction in the incidence of sore throat right after extubation at rest and swallowing, a clear advantage of a significant reduction in the incidence of sore throat on swallowing from the two hour period after extubation was observed.

There was no associated risk of local or systemic toxicity as the dose used was around one-tenth of the systemically used dose for the treatment of pre-eclampsia and eclampsia and the mucosal drug absorption would not anywhere match the systemic levels of parenteral administration of the same drug similar to the conclusions of by Blitz et $a l .{ }^{(17)}$ who used nebulized magnesium sulphate for treatment of acute asthma. ${ }^{(18)}$ The mucosal absorption although stated to be variable is also low to the level of around $10 \%$.The drawback of our study was the absence of the measurements of serum magnesium levels making it difficult to rule out the contribution of systemic effects of magnesium.

In our study, magnesium sulphate nebulisation reduced the incidence of post-operative sore throat at rest after four hours with a significant difference compared to the group which received nebulisation with normal saline. Magnesium sulphate group also had a significantly lesser incidence of post-operative sore throat on swallowing after two hours in comparison to the normal saline nebulisation group. 


\section{Conclusion}

On analysing the results of the study, one can reasonably conclude that magnesium sulphate does reduce the incidence of POST in a significant manner. The low dose use of magnesium sulphate in the nebulised format ensures that the incidence of systemic toxicity is near zero. The availability of magnesium sulphate is also easy and hence its utilisation has a wide range of scope in many areas of anaesthetic practice, especially with regard to the prevention of POST.

\section{Reference}

1. Sumathi PA, Shenoy T, Ambareesha M, Krishna HM. Controlled comparison between betamethasone gel and lidocaine jelly applied over tracheal tube to reduce postoperative sore throat, cough, and hoarseness of voice. Br J Anaesth. 2008 Feb;100(2):215-8.

2. Bidwai AV, Bidwai VA, Rogers CR, Stanley TH. Blood-pressure and pulse-rate responses to endotracheal extubation with and without prior injection of lidocaine. Anesthesiology. 1979 Aug;51(2):171-3.

3. Santra S, Das B. Effect of propofol and thiopentone on intracranial pressure and cerebral perfusion pressure in patients undergoing elective craniotomy - a comparative study. Indian J Anaesth. 2007 May 1;51(3):211.

4. Bartlett D, Jeffery P, Sant'ambrogio G, Wise JC. Location of stretch receptors in the trachea and bronchi of the dog. J Physiol. 1976 Jun;258(2):409-20.

5. Camporesi EM. Mortola JP. SantsAmbrozio F, Sant'sAmbrozio G. Topical anaesthesia of tracheal receptors. ApplPhysiol 197947 1123-6.

6. http://reference.medscape.com/drug/mgso4 -magnesium-sulfate-344444.

7. Lin CY, Tsai PS, Hung YC, Huang CJ. Ltype calcium channels are involved in mediating the anti-inflammatory effects of magnesium sulphate. Br J Anaesth. 2010 Jan;104(1):44-51.

8. Zhu MM, Zhou QH, Zhu MH, Rong HB, $\mathrm{Xu}$ YM, Qian YN, et al. Effects of nebulized ketamine on allergen-induced airway hyperresponsiveness and inflammation in actively sensitized BrownNorway rats. J InflammLond Engl. 2007 May 4;4:10.

9. Turpin F, Dallérac G, Mothet J-P. Electrophysiological analysis of the modulation of NMDA-receptors function by $\mathrm{D}$-serine and glycine in the central nervous system. Methods MolBiol Clifton NJ. 2012;794:299-312.

10. Ratnaraj J, Todorov A, McHugh T, Cheng MA, Lauryssen C. Effects of decreasing endotracheal tube cuff pressures during neck retraction for anterior cervical spine surgery. J Neurosurg. 2002 Sep;97(2 Suppl):176-9.

11. Inflammation-induced changes in peripheral glutamate receptor populations. - PubMed - NCBI [Internet]. [cited 2018 Sep 19]. Available from: https://www.ncbi.nlm.nih.gov/pubmed/100 23031

12. Carlton SM, Coggeshall RE. Inflammation-induced changes in peripheral glutamate receptor populations. Brain Res. 1999 Feb 27;820(1-2):63-70.

13. Kori K, Muratani T, Tatsumi S, Minami T. [Influence of endotracheal tube cuff lubrication on postoperative sore throat and hoarseness]. Masui. 2009 Mar;58(3):342-5.

14. Maruyama K, Sakai H, Miyazawa H, Iijima $\mathrm{K}$, Toda $\mathrm{N}$, Kawahara $\mathrm{S}$, et al. Laryngotracheal application of lidocaine spray increases the incidence of postoperative sore throat after total intravenous anesthesia. $\mathrm{J}$ Anesth. 2004;18(4):237-40. 
15. Borazan H, Kececioglu A, Okesli S, Otelcioglu S. Oral magnesium lozenge reduces postoperative sore throat: a randomized, prospective, placebocontrolled study. Anesthesiology. 2012 Sep;117(3):512-8.

16. Gupta SK, Tharwani S, Singh DK, Yadav G. Nebulized magnesium for prevention of postoperative sore throat. BJA $\mathrm{Br} \quad \mathrm{J}$ Anaesth. 2012 Jan 1;108(1):168-9.

17. Blitz M, Blitz S, Hughes R, Diner B, Beasley R, Knopp J, et al. Aerosolized magnesium sulfate for acute asthma: a systematic review. Chest. 2005 Jul;128 (1):337-44.

18. Nebulizers: principles and performance. PubMed - NCBI [Internet]. [cited 2018 Sep 19]. Available from: https://www.ncbi.nlm.nih.gov/pubmed/108 94454. 